\title{
Electron beam induced etching of carbon
}

\author{
Aiden A. Martin, ${ }^{1}$ Geoffrey McCredie, ${ }^{1}$ and Milos Toth $^{1,}$ a) \\ School of Physics and Advanced Materials, University of Technology, \\ Sydney, 15 Broadway, Ultimo, New South Wales 2007, \\ Australia
}

(Dated: 16 June 2015)

Nanopatterning of graphene and diamond by low energy $(\leq 30 \mathrm{keV})$ electrons has previously been attributed to mechanisms that include atomic displacements caused by knock-on, electron beam heating, sputtering by ionized gas molecules, and chemical etching driven by a number of gases that include $\mathrm{N}_{2}$. Here we show that a number of these mechanisms are insignificant, and that the nanopatterning process can instead be explained by etching caused by electron induced dissociation of residual $\mathrm{H}_{2} \mathrm{O}$ molecules. Our results have significant practical implications for gas-mediated electron beam nanopatterning techniques and help elucidate the underlying mechanisms.

a)Electronic mail: Milos.Toth@uts.edu.au 
Nanopatterning of graphene ${ }^{1}$ and diamond ${ }^{2,3}$ has attracted interest due the unique electrical $^{4}$ and optical ${ }^{5}$ properties of these materials. They are however, sensitive to doping levels and defects in the crystal structure which can be affected by the processing method ${ }^{6,7}$. Gas-mediated electron beam induced etching ${ }^{8,9}$ (EBIE) is increasingly being used for rapid prototyping of functional structures in graphene ${ }^{10}$ and diamond ${ }^{11}$ as it eliminates damage to the material produced by masking and ion implantation.

In the EBIE process, gaseous precursor molecules are delivered to the substrate surface where they are dissociated by an electron beam, producing reactive fragments which give rise to volatilization of the substrate. EBIE has been used to etch numerous carbon materials including graphene $\mathrm{1}^{10,12-15}$, carbon nanotubes ${ }^{16-19}$, diamond ${ }^{11,20-22}$, ultra nano-crystalline diamond $^{23}$ (UNCD), and amorphous carbon-rich nanowires ${ }^{24,25}$ and films ${ }^{18,24,26-28}$. At low electron beam energies $(\leq 30 \mathrm{keV})$, where atomic displacements by knock-on collisions between electrons and carbon are negligible ${ }^{14,29,30}$, the removal of carbon is typically attributed to chemical etching (i.e. volatilization of carbon). The etching is generally ascribed to chemical pathways that involve $\mathrm{O}^{*}, \mathrm{H}^{*}$ or $\mathrm{OH}^{*}$ radicals produced by electron induced dissociation of $\mathrm{H}_{2} \mathrm{O}^{11,14,16,18,22,23,27,28}, \mathrm{O}_{2}{ }^{10,13,14,16,17,19,20,22,26}, \mathrm{NH}_{3}{ }^{25}$ or $\mathrm{H}_{2}{ }^{16,21}$ precursor molecules adsorbed to the surface of the etched material.

Electron beam nanopatterning of carbon materials has, surprisingly, also been demonstrated using $\mathrm{N}_{2}$ as the precursor gas. Specifically, it has been reported that electron beam induced removal of carbon from graphene ${ }^{12}$ and diamond ${ }^{22}$ can be accelerated by introducing $\mathrm{N}_{2}$ into the vacuum chamber. These observations were attributed to sputtering ${ }^{22}$ and chemical etching ${ }^{12}$ of carbon caused by nitrogen ions. Here we demonstrate that the injection of not only $\mathrm{N}_{2}$, but also Ar can indeed be used to increase the removal rate of carbon irradiated by an electron beam. However, we show that this increase can be eliminated using an appropriate experimental configuration, and can not be explained by chemical etching caused by these gases, nor by sputtering caused by ionized gas molecules. Instead, it is ascribed to EBIE caused by residual $\mathrm{H}_{2} \mathrm{O}$ molecules whose flow rate to the etched material is increased by the injection of $\mathrm{N}_{2}$ and Ar into the vacuum chamber. We also propose that the combination of $\mathrm{H}_{2} \mathrm{O}$ and hydrocarbon contaminants can, in principle, explain unexpected behavior that has been observed recently in graphene and attributed to mechanisms that include electron beam induced heating and atomic displacements caused by knock-on (at electron beam energies as low as $5 \mathrm{keV})^{15}$. 
We start by showing that low energy electron beams can be used to remove carbon from a range of materials in a high vacuum $\left(3 \times 10^{-4} \mathrm{~Pa}\right)$ environment. Electron beam processing was performed at room temperature using a field emission gun scanning electron microscope (SEM) described elsewhere ${ }^{25}$. Hydrocarbon contamination in the vacuum system was minimized by plasma cleaning ${ }^{31}$ the SEM chamber using an XEI Scientific Evactron for $\sim 12$ hours $\left(\mathrm{RF}\right.$ power $=13 \mathrm{~W}, \mathrm{O}_{2}$ pressure $\left.=40 \mathrm{~Pa}\right)$ prior to loading substrates into the system, and heating substrates in-situ using the conditioning procedures detailed in the Supplementary Material ${ }^{32}$. Fig. 1 shows regions of graphene and lacey carbon, each of which was removed by scanning a $10 \mathrm{keV}, 1.3 \mathrm{nA}$ focused beam over an area of $200 \times 200 \mathrm{~nm}$ for 30 and 20 minutes, respectively. Fig. 2(a) and Table I show the depths of pits made in UNCD in high vacuum (and in $\mathrm{Ar}$ and $\mathrm{N}_{2}$ environments, under a number of conditions detailed below). These results illustrate that the injection of a precursor gas into a high vacuum SEM is not required for the removal of carbon, which we attribute to $\mathrm{H}_{2} \mathrm{O}$-mediated EBIE. $\mathrm{H}_{2} \mathrm{O}$ is the most abundant species present in this vacuum regime ${ }^{33}$ and is known to give rise to etching under electron irradiation ${ }^{34}$.

\begin{tabular}{|l|c|c|r|c|}
\hline Environment & $\begin{array}{c}\text { Depth } \\
(\mathrm{nm})\end{array}$ & $\begin{array}{c}\text { Average depth } \\
(\mathrm{nm})\end{array}$ & $\begin{array}{r}\text { Gas line } \\
\text { pump (K) }\end{array}$ & $\begin{array}{c}\text { eCell } \\
\text { pump (K) }\end{array}$ \\
\hline High vacuum & 62,37 & 50 & 298 & 298 \\
\hline $\mathrm{Ar}$ & $48,64,50,54$ & 54 & $\sim 77$ & $\sim 218$ \\
\hline $\mathrm{Ar}$ & $234,196,220$ & 217 & $\sim 77$ & 298 \\
\hline $\mathrm{Ar}$ & 417 & 417 & 298 & 298 \\
\hline $\mathrm{N}_{2}$ & 169 & 169 & $\sim 77$ & 298 \\
\hline
\end{tabular}

TABLE I. Depths of pits produced in UNCD using an electron beam under a number of environmental conditions. The two cryogenic pumps are shown in Fig. 2(b).

To confirm the role of $\mathrm{H}_{2} \mathrm{O}$ in the observed carbon removal process, a set of $\sim 6.6 \mu \mathrm{m}$ diameter pits (summarized in Fig. 2(a) and Table I) were fabricated in high vacuum, and at $\mathrm{N}_{2}$ and Ar pressures of $13 \mathrm{~Pa}$. The experiments were performed using a UNCD substrate, a $20 \mathrm{keV}$ stationary top-hat electron beam with a diameter of $\sim 6.6 \mu \mathrm{m}$, and the vacuum system configuration based on the environmental reaction cell (eCell) shown in Fig. 2(b). The UNCD substrates were $\sim 1.7 \mu \mathrm{m}$ films grown on silicon by hot filament chemical vapor 
deposition (HFCVD) at $953 \mathrm{~K}$ (grain size $=25 \mathrm{~nm}$, average roughness $=10 \mathrm{~nm})^{35}$ (for a complete list of experimental parameters and a description of the eCell, see the Supplementary Material $^{32}$ ). UNCD was used because $\mathrm{H}_{2} \mathrm{O}$-mediated EBIE of UNCD has been characterized previously over a range of beam energies ( 5 to $20 \mathrm{keV}$ ), and the etch kinetics are well understood $^{23}$. The broad, stationary beam with a top-hat electron flux profile was used (instead of a highly focused, scanned Gaussian beam) because this configuration improves reproducibility and quantitative analysis of pits made by an electron beam ${ }^{23,36}$. The eCell shown in Fig. 2(b) was used (instead of a conventional cappilary-style gas injection system ${ }^{37}$ ) because it improves the degree of control over the vacuum chamber environment ${ }^{25,38}$, and enables EBIE experiments to be performed with a high degree of reproducibility ${ }^{23}$. Two liquid nitrogen (LN) cold traps were installed, one on a gas delivery line and one inside the eCell (see Fig. 2(b)) to enable optional cryogenic pumping of gaseous contaminants present in the vacuum system. Depths of pits were measured ex situ using the tapping mode of a DI Dimension 3100 atomic force microscope (AFM), and analyzed using the software package Gwyddion ${ }^{39}$.

First, we compare pits made in UNCD with both cryogenic pumps disabled. The depths of pits made in high vacuum and an Ar environment were 37-62 nm and $417 \mathrm{~nm}$, respectively, as shown in Table I (for a full description of the experiment, see the Conditioning Procedures section of the Supplementary Material ${ }^{32}$ ). The variation observed in high vacuum depends on the procedure used to reach the irradiation conditions. If the UNCD is irradiated immediately after pumping down to a pressure of $3 \times 10^{-4} \mathrm{~Pa}$, the pit depth $(62 \mathrm{~nm})$ is greater than when the system is pumped for an extended period of time prior to irradiation (37 nm). This is consistent with a decrease in the concentration of residual $\mathrm{H}_{2} \mathrm{O}$ in the vacuum system. The increase in carbon removal rate caused by Ar can, in principle, be explained by residual $\mathrm{H}_{2} \mathrm{O}$ contaminants since the injection of gases into a vacuum chamber can increase the partial pressure of $\mathrm{H}_{2} \mathrm{O}^{40}$. To test this hypothesis, the cryogenic pump installed on the gas delivery line shown in Fig. 2(b) was cooled from $298 \mathrm{~K}$ to $\sim 77 \mathrm{~K}$ while Ar was flowing into the vacuum chamber, yielding pit depths in the range of 196-234 $\mathrm{nm}$. The reduction in pit depth (from $417 \mathrm{~nm}$ to 196-234 nm) caused by cooling of the cryogenic pump is consistent with the proposal that the increase in carbon removal rate observed upon the introduction of $\mathrm{Ar}$ is caused by the delivery of $\mathrm{H}_{2} \mathrm{O}$ impurities to the UNCD substrate.

Next, the cryogenic pump installed inside the eCell shown in Fig. 2(b) was cooled from 
$298 \mathrm{~K}$ to $\sim 218 \mathrm{~K}$. After conditioning (see the Conditioning Procedures section of the Supplementary Material ${ }^{32}$ ), a series of 4 electron irradiations in an Ar environment produced pit depths in the range of $48-64 \mathrm{~nm}$. These results are comparable to the depths of $37-$ $62 \mathrm{~nm}$ produced in high vacuum, and show that cryogenic pumping can be used to eliminate the enhancement in carbon removal rate caused by the injection of an inert gas into a high vacuum process chamber.

To compare pits made in $\mathrm{N}_{2}$ and Ar environments, the system was conditioned (see the Conditioning Procedures section of the Supplementary Material ${ }^{32}$ ) with the gas delivery line cryogenic pump cooled to $\sim 77 \mathrm{~K}$. Electron irradiation in an $\mathrm{N}_{2}$ environment produced a pit depth of $169 \mathrm{~nm}$. Hence, the results summarized in Table I illustrate that the introduction of either $\mathrm{N}_{2}$ or Ar to a high vacuum chamber can cause a significant increase in the carbon removal rate. However, given that $\mathrm{N}_{2}$ does not increase the removal rate relative to Ar, the mechanism of chemical etching by nitrogen ions (leading to the production of volatile cyanogen $\left(\mathrm{CN}_{2}\right)$ molecules) proposed by Fox et. al. ${ }^{12}$ is likely insignificant. We note that the production of $\mathrm{CN}_{2}$ has been demonstrated with activated nitrogen at elevated temperatures ${ }^{41}$, but not under the conditions used for electron beam induced removal of carbon.

The above results, summarized in Fig. 2(a) and Table I, can not be explained by chemical etching caused by the gases injected into the vacuum system ${ }^{12}$ or sputtering ${ }^{22}$ caused by nitrogen or argon ions. They are, however, consistent with: (i) EBIE caused by $\mathrm{H}_{2} \mathrm{O}$ contaminants present in the high vacuum chamber, and (ii) an increase in the $\mathrm{H}_{2} \mathrm{O}$ delivery rate to the sample by $\mathrm{N}_{2}$ and Ar gases. The difference between pit depths produced whilst cooling one (196-234 nm) and both (48-64 nm) cryogenic pumps in an Ar environment indicates that most of the extra $\mathrm{H}_{2} \mathrm{O}$ evolves from gas delivery plumbing and vacuum system walls exposed to the flowing Ar gas.

Next, we show that under the conditions used to perform the above experiments in high vacuum, $\mathrm{N}_{2}$ and Ar environments, the surface of the etched material is covered predominantly by $\mathrm{H}_{2} \mathrm{O}$ molecules. In the absence of electron irradiation, the concentration of surface-adsorbed molecules $(N)$ is found by solving 8 :

$$
\frac{d N}{d t}=s F(1-\Theta)-N / \tau
$$

where $s F(1-\Theta)$ is the flux of gas molecules adsorbing to the surface, $N / \tau$ is the desorption 
flux, $s$ is the sticking coefficient, $F$ is the gas molecule flux incident onto the surface $(F=$ $P\left(\sqrt{2 \pi m k T_{g}}\right), \mathrm{P}$ is pressure, $m$ is the gas molecule mass, $k$ is Boltzmann's constant, $T_{g}$ is gas temperature, $\Theta$ is the adsorbate coverage (which is typically limited to one monolayer by the Langmuir isotherm, $\Theta=A N), A$ is the area of a single surface site and $\tau$ is the adsorbate residence time:

$$
\tau=\tau_{0} e^{E / k T}
$$

where $\tau_{0}$ is the reciprocal desorption attempt frequency, $E$ is the activation energy for thermal desorption and $T$ is the temperature of the surface. Eqn. 1 has the steady state solution:

$$
N_{\infty}=\frac{s F}{s F A+1 / \tau},
$$

which, at $298 \mathrm{~K}$, yields a $\mathrm{H}_{2} \mathrm{O}$ concentration of $1.5 \times 10^{10} \mathrm{~cm}^{-2}$ at a pressure of $3 \times 10^{-4} \mathrm{~Pa}$, $\mathrm{N}_{2}$ concentration of $9.4 \times 10^{9} \mathrm{~cm}^{-2}$ at $13 \mathrm{~Pa}$ and $\mathrm{Ar}$ concentration of $4.7 \times 10^{9} \mathrm{~cm}^{-2}$ at $13 \mathrm{~Pa}$ (a complete list of parameters used in Eqn. 3 is provided in the Modeling Parameters section of the Supplementary Material ${ }^{32}$ ). The dependencies of these concentrations on pressure is plotted in Fig. 3. The plot shows that, over the range of pressures encountered in high vacuum EBIE systems, the concentration of $\mathrm{H}_{2} \mathrm{O}$ adsorbates is always greater than or similar to that of $\mathrm{N}_{2}$ or Ar. This is caused by the significantly higher adsorption energy of $\mathrm{H}_{2} \mathrm{O}$ on all surfaces. Given the rate of EBIE scales with the concentration of surfaceadsorbed precursor molecules ${ }^{8,9}$, the above results show that residual $\mathrm{H}_{2} \mathrm{O}$ adsorbates must be considered when interpreting electron irradiation experiments performed in high vacuum systems, as well as changes in the supply rate of $\mathrm{H}_{2} \mathrm{O}$ caused by the injection of gases into an EBIE chamber.

Finally, we note that many medium and long chain hydrocarbons have high adsorption energies on common surfaces ${ }^{8,42}$, and the role of residual hydrocarbon contaminants must not be overlooked when interpreting electron beam irradiation experiments. Hydrocarbon impurities are common in high vacuum systems and give rise to electron beam induced deposition (EBID) of amorphous carbonaceous materials ${ }^{34}$. In the present work, this EBID process was minimized by using the conditioning procedures described above and in the Supplementary Material ${ }^{32}$. However, when such procedures are not employed, and standard electron microscopes are used for $\mathrm{H}_{2} \mathrm{O}$-mediated EBIE, deposition of amorphous carbon-rich material competes with etching ${ }^{25,27,43}$. The material deposited by EBID is simultaneously 
etched and restructured (damaged) by the electron beam. The restructuring makes the material non-uniform, generating nano-clusters with locally modified etch rates ${ }^{24}$. The net effect of such simultaneous EBID, restructuring and EBIE is a complex dependence of etch rate on parameters such as the electron beam energy, current, flux and scan rate ${ }^{24,27}$. In particular, the etch rate can increase with increasing scan rate, and the restructuring rate can increase with decreasing electron beam energy. These dependencies provide an alternate explanation to behavior that has recently been ascribed to knock-on displacements of atoms from graphene (by electrons with energies as low as $5 \mathrm{keV}$ ) and electron beam induced heating of graphene ${ }^{15}$.

In conclusion, the injection of inert gases into a high vacuum chamber was shown to increase the removal rate of carbon from UNCD by a low energy electron beam. It is caused by an increase in the concentration of residual $\mathrm{H}_{2} \mathrm{O}$ adsorbates at the sample, and can be eliminated using an appropriate vacuum system configuration.

This work was funded in part by FEI Company and the Australian Research Council (Project Number DP140102721). A.A.M. is the recipient of a John Stocker Postgraduate Scholarship from the Science and Industry Endowment Fund. 
FIG. 1. (Color online) Electron beam induced removal of carbon from (a) graphene and (b) lacy carbon.

FIG. 2. (Color online) (a) Depths of pits produced in UNCD using an electron beam under the environmental conditions listed in Table I: $(\bullet)$ high vacuum, $(\boldsymbol{\Delta}) \mathrm{N}_{2}$ with only the gas line cryogenic pump cooled, $(\times)$ Ar with no cryogenic pumps cooled, $(\diamond)$ Ar with only the gas line cryogenic pump cooled, and ( $\mathbf{\square})$ Ar with both cryogenic pumps cooled. Markers and lines indicate the average and the range of pit depths produced under each set of conditions, respectively. Inset: AFM image of an etch pit produced in UNCD. (b) Simplified schematic of the system including the gas delivery system, eCell, and LN cryogenic pumps connected to the gas delivery line and eCell.

FIG. 3. (Color online) Concentration $(N)$ of $\mathrm{H}_{2} \mathrm{O}, \mathrm{N}_{2}$ and $\mathrm{Ar}$ adsorbates calculated as a function of pressure. 


\section{REFERENCES}

${ }^{1}$ J. Feng, W. Li, X. Qian, J. Qi, L. Qi, and J. Li, Nanoscale 4, 4883 (2012).

${ }^{2}$ S. Castelletto, J. P. Harrison, L. Marseglia, A. C. Stanley-Clarke, B. C. Gibson, B. A. Fairchild, J. P. Hadden, Y. D. Ho, M. P. Hiscocks, K. Ganesan, S. T. Huntington, F. Ladouceur, A. D. Greentree, S. Prawer, J. L. O'Brien, and J. G. Rarity, New J. Phys. 13, 025020 (2011).

${ }^{3}$ M. Loncar and A. Faraon, MRS Bull. 38, 144 (2013).

${ }^{4}$ A. H. Castro Neto, N. M. R. Peres, K. S. Novoselov, and A. K. Geim, Rev. Mod. Phys. 81, 109 (2009).

${ }^{5}$ I. Aharonovich, S. Castelletto, D. A. Simpson, C. Su, A. D. Greentree, and S. Prawer, Rep. Prog. Phys. 74, 076501 (2011).

${ }^{6}$ Y. Dan, Y. Lu, N. J. Kybert, Z. Luo, and A. T. C. Johnson, Nano Lett. 9, 1472 (2009).

${ }^{7}$ I. Bayn, A. Bolker, C. Cytermann, B. Meyler, V. Richter, J. Salzman, and R. Kalish, Appl. Phys. Lett. 99, 183109 (2011).

${ }^{8}$ I. Utke, S. Moshkalev, and P. Russell, Nanofabrication Using Focused Ion and Electron Beams: Principles and Applications (Oxford University Press, New York, 2012).

${ }^{9}$ M. Toth, Appl. Phys. A: Mater. Sci. Process. 117, 1623 (2014).

${ }^{10}$ C. Thiele, A. Felten, T. J. Echtermeyer, A. C. Ferrari, C. Casiraghi, H. von Löhneysen, and R. Krupke, Carbon 64, 84 (2013).

${ }^{11}$ A. A. Martin, M. Toth, and I. Aharonovich, Sci. Rep. 4, 5022 (2014).

${ }^{12}$ D. Fox, A. ONeill, D. Zhou, M. Boese, J. N. Coleman, and H. Z. Zhang, Appl. Phys. Lett. 98, 243117 (2011).

${ }^{13}$ S. Goler, V. Piazza, S. Roddaro, V. Pellegrini, F. Beltram, and P. Pingue, J. Appl. Phys. 110, 064308 (2011).

${ }^{14}$ J. C. Meyer, F. Eder, S. Kurasch, V. Skakalova, J. Kotakoski, H. J. Park, S. Roth, A. Chuvilin, S. Eyhusen, G. Benner, A. V. Krasheninnikov, and U. Kaiser, Phys. Rev. Lett. 108, 196102 (2012).

${ }^{15}$ Y. Lan, W. Chang, B. Xiao, B. Liang, J. Chen, P. Jiang, L. Li, Y. Su, Y. Zhong, and C. Chen, Small 10, 4778 (2014).

${ }^{16}$ T. D. Yuzvinsky, A. M. Fennimore, W. Mickelson, C. Esquivias, and A. Zettl, Appl. Phys. Lett. 86, 053109 (2005). 
${ }^{17}$ P. Liu, F. Arai, and T. Fukuda, in IEEE-NANO 2006. Sixth IEEE Conference on Nanotechnology, Vol. 2, pp. 540-543, 17-20 June, 2006, Cincinnati, OH, U.S.A. (Institute of Electrical and Electronics Engineers, New York, 2006).

${ }^{18}$ P. S. Spinney, D. G. Howitt, S. D. Collins, and R. L. Smith, Nanotechnology 20, 465301 (2009).

${ }^{19}$ C. Thiele, M. Engel, F. Hennrich, M. M. Kappes, K.-P. Johnsen, C. G. Frase, H. V. Loehneysen, and R. Krupke, Appl. Phys. Lett. 99, 173105 (2011).

${ }^{20}$ J. Taniguchi, I. Miyamoto, N. Ohno, and S. Honda, Jpn. J. Appl. Phys. 35, 6574 (1996).

${ }^{21}$ J. Taniguchi, I. Miyamoto, N. Ohno, K. Kantani, M. Komuro, and H. Hiroshima, Jpn. J. Appl. Phys. 36, 7691 (1997).

${ }^{22}$ J. Niitsuma, X. Yuan, S. Koizumi, and T. Sekiguchi, Jpn. J. Appl. Phys. 45, L71 (2006).

${ }^{23}$ A. Martin, M. Phillips, and M. Toth, ACS Appl. Mater. Interfaces 5, 8002 (2013).

${ }^{24}$ M. Toth, C. Lobo, W. Knowles, M. Phillips, M. Postek, and A. Vladár, Nano Lett. 7, 525 (2007).

${ }^{25}$ C. J. Lobo, A. Martin, M. R. Phillips, and M. Toth, Nanotechnology 23, 375302 (2012).

${ }^{26}$ D. Wang, P. Hoyle, J. Cleaver, G. Porkolab, and N. Macdonald, J. Vac. Sci. Technol., B 13, $1984(1995)$.

${ }^{27}$ M. Toth, C. J. Lobo, G. Hartigan, and W. Ralph Knowles, J. Appl. Phys. 101, 054309 (2007).

${ }^{28}$ H. Miyazoe, I. Utke, J. Michler, and K. Terashima, Appl. Phys. Lett. 92, 043124 (2008).

${ }^{29}$ A. V. Krasheninnikov and F. Banhart, Nat. Mater. 6, 723 (2007).

${ }^{30}$ F. Banhart, Rep. Prog. Phys. 62, 1181 (1999).

${ }^{31}$ T. C. Isabell, P. E. Fischione, C. O'Keefe, M. U. Guruz, and V. P. Dravid, Microsc. Microanal. 5, 126 (2002).

${ }^{32}$ See Supplemental Material at http://.................... for a detailed description of experimental methods and model input parameters.

${ }^{33}$ A. T. Marshall, J. Microsc. (Oxford, U. K.) 133, 119 (1984).

${ }^{34}$ J. J. Hren, Introduction to Analytical Electron Microscopy, edited by J. J. Hren, J. I. Goldstein, and D. C. Joy (Plenum Press, New York, 1979).

${ }^{35}$ V. Adiga, A. Sumant, S. Suresh, C. Gudeman, O. Auciello, J. Carlisle, and R. Carpick, Phys. Rev. B: Condens. Matter Mater. Phys. 79, 245403 (2009).

${ }^{36}$ A. A. Martin and M. Toth, ACS Appl. Mater. Interfaces 6, 18457 (2014). 
${ }^{37}$ I. Utke, P. Hoffmann, and J. Melngailis, J. Vac. Sci. Technol., B 26, 1197 (2008).

${ }^{38}$ J. Bishop, C. Lobo, A. Martin, M. Ford, M. Phillips, and M. Toth, Phys. Rev. Lett. 109, 146103 (2012).

${ }^{39}$ D. Nečas and P. Klapetek, Cent. Eur. J. Phys. 10, 181 (2012).

${ }^{40}$ A. Perentes, G. Sinicco, G. Boero, B. Dwir, and P. Hoffmann, J. Vac. Sci. Technol., B 25, 2228 (2007).

${ }^{41}$ H. W. Goldstein, J. Phys. Chem. 68, 39 (1964).

${ }^{42}$ S. M. Wetterer, D. J. Lavrich, T. Cummings, S. L. Bernasek, and G. Scoles, J. Phys. Chem. B 102, 9266 (1998).

${ }^{43}$ M. Toth, C. J. Lobo, M. J. Lysaght, A. E. Vladar, and M. T. Postek, J. Appl. Phys. 106, $034306(2009)$. 
(b) $\searrow$

(a) 


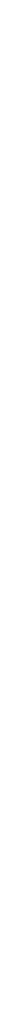

